Role of $\beta-1,3 ; 1,4-g l u c a n$ in the cell wall architecture of

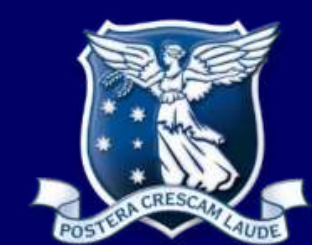

THE UNIVERSITY O MELBOURNE

\section{Talaromyces marneffei}

Aakash Gupta ${ }^{1}$, Alex Andrianopoulos ${ }^{2}$

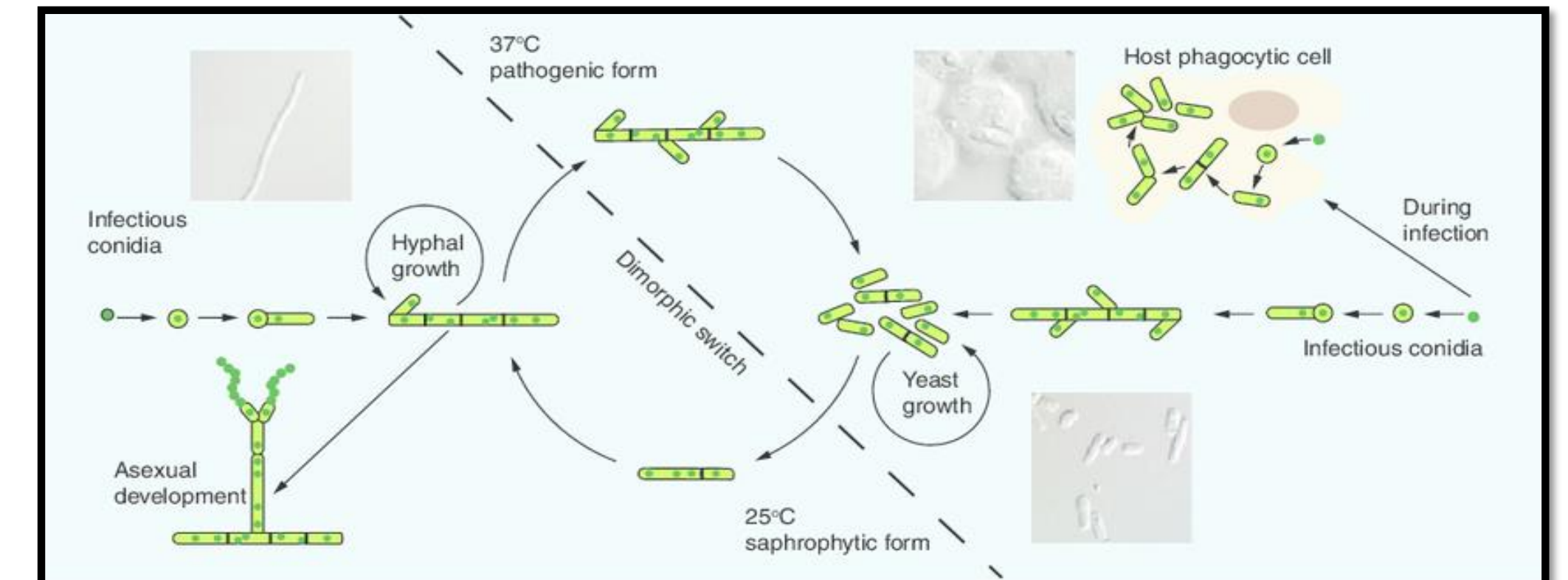

School of Biosciences, University of Melbourne, Parkville, Australia

Aim

This project is aimed at describing the cell wall architecture of $T$. marneffei while focussing on a crucial component of the cell wall ( $\beta-1,3 ; 1,4-$ glucan/Mixed linkage glucan) and its role in growth and pathogenicity

\section{1. $\beta-1,3 ; 1,4$-glucan distribution in T. marneffei} Cell wall of spores, yeast cell(In-vitro) and yeast cell(ex-vivo) are triple layered as opposed to bilayer cell wall of hyphae where MLG is mainly distributed in between two electron dense layers.

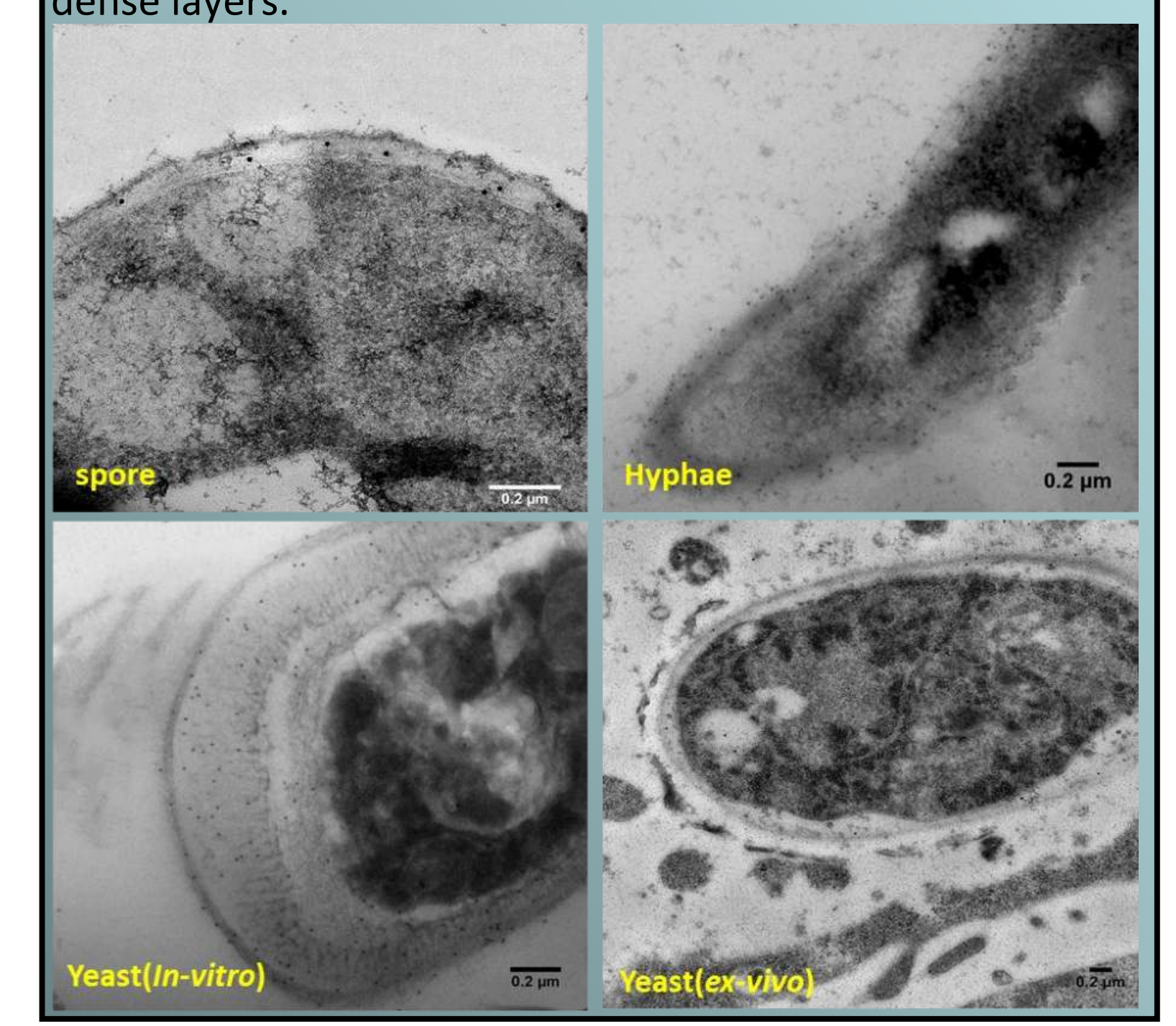

4. Increased resistance to antifungal agents (Caspofungin)

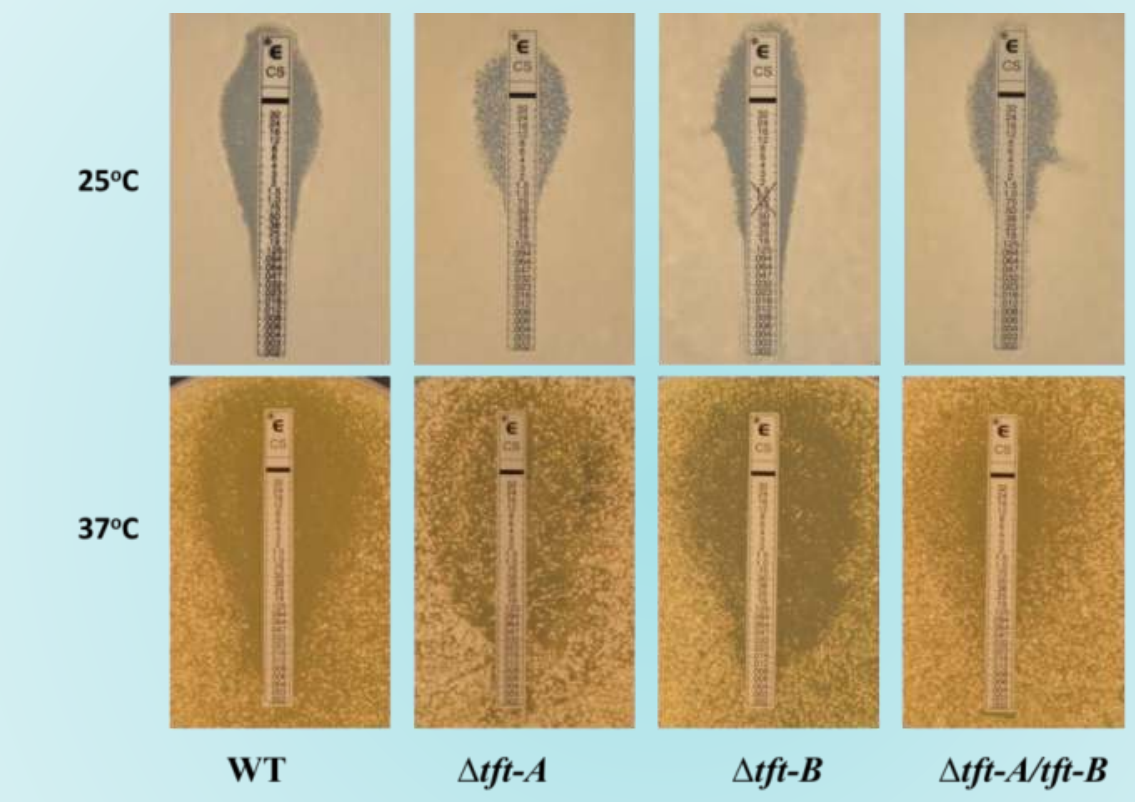

\begin{tabular}{|c|cccc|}
\hline & WT & $\Delta t f t-A$ & $\Delta t f t-B$ & $\Delta t f t-A / \Delta t f t-B$ \\
\hline MIC- $\mu \mathrm{g} / \mathrm{ml}\left(25^{\circ} \mathrm{C}\right)$ & 0.032 & 0.50 & 0.047 & 0.25 \\
$\mathrm{MIC}-\mu \mathrm{g} / \mathrm{ml}\left(37^{\circ} \mathrm{C}\right)$ & 0.003 & 0.016 & 0.08 & 0.064 \\
\hline
\end{tabular}

Conclusion

Tft-A is the major contributor to the synthesis of mixed linkage glucan.

MLG is crucial in maintaining hyphal and yeast cell morphology as mutants devoid of MLG have aberrant growth phenotype.
2. Phenotypic effect of mix linkage glucan mutants on spore size

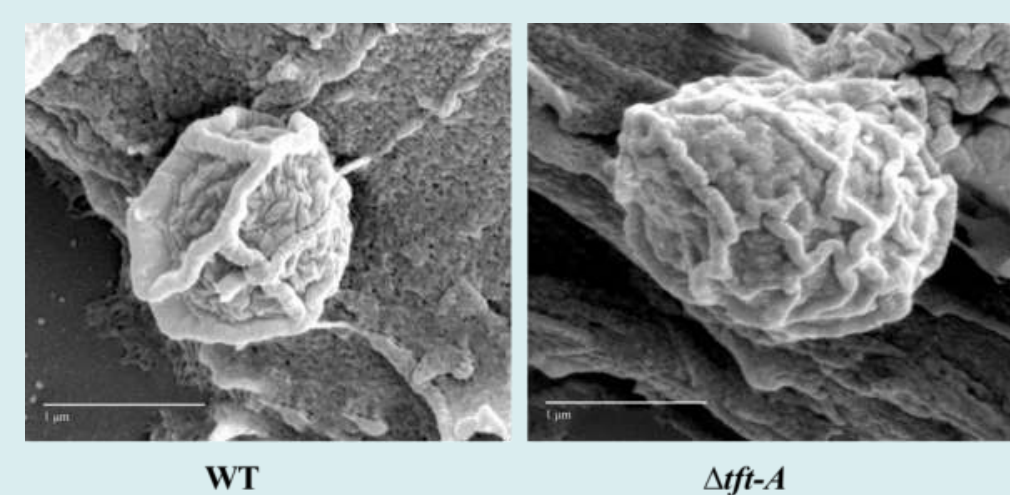

WT

- Spore size of $\Delta t f t-A$ and $\Delta t f t-A / \Delta t f t-B$ was larger than the wild type suggesting that other cell wall genes might have overcompensated for the loss of mixed linkage glucans.

- Mis assembly of rodlet layer was also observed in $\Delta t f t-A$ and $\Delta t f t-A / \Delta t f t-B$

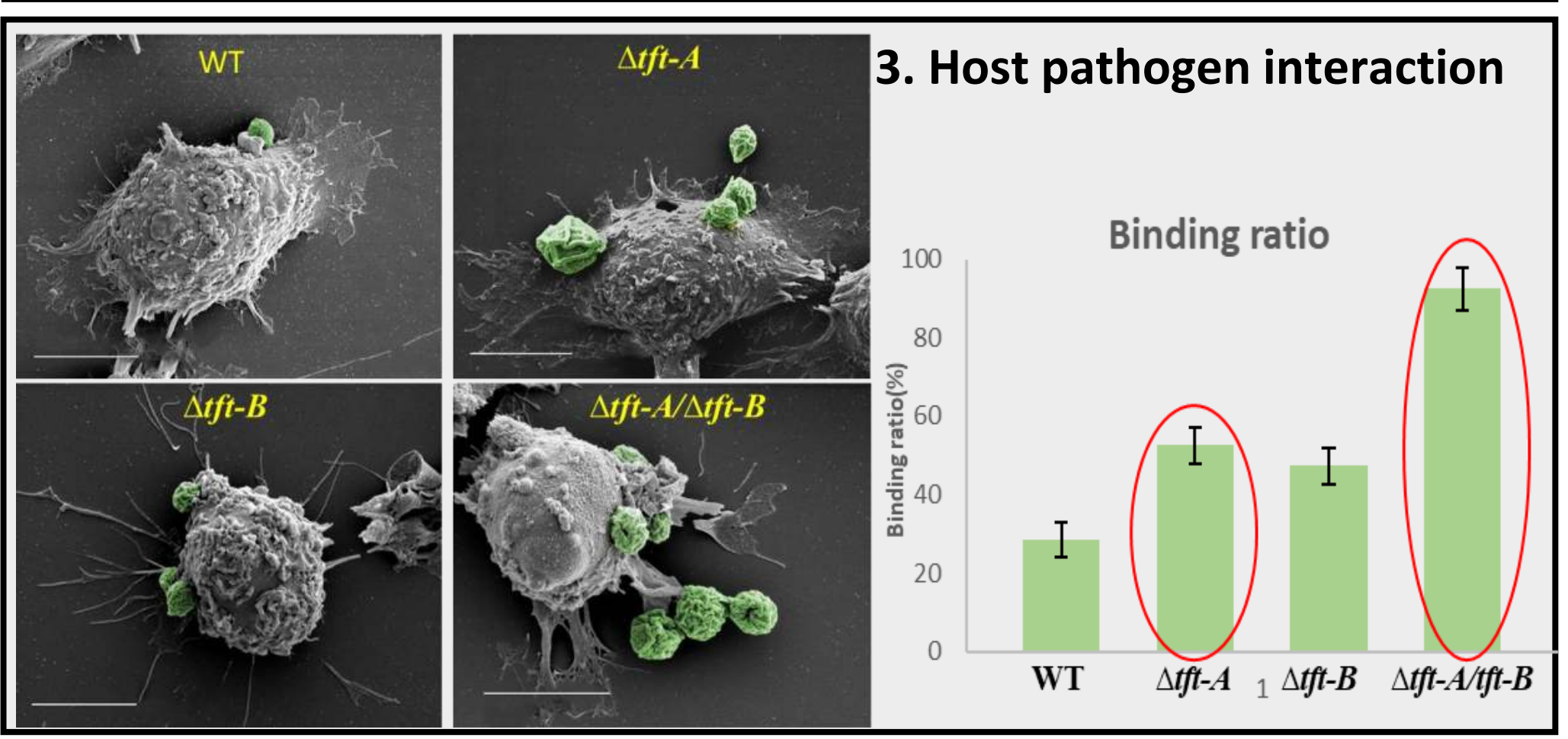

5. Expression profiles of cell wall related genes in mutants devoid of
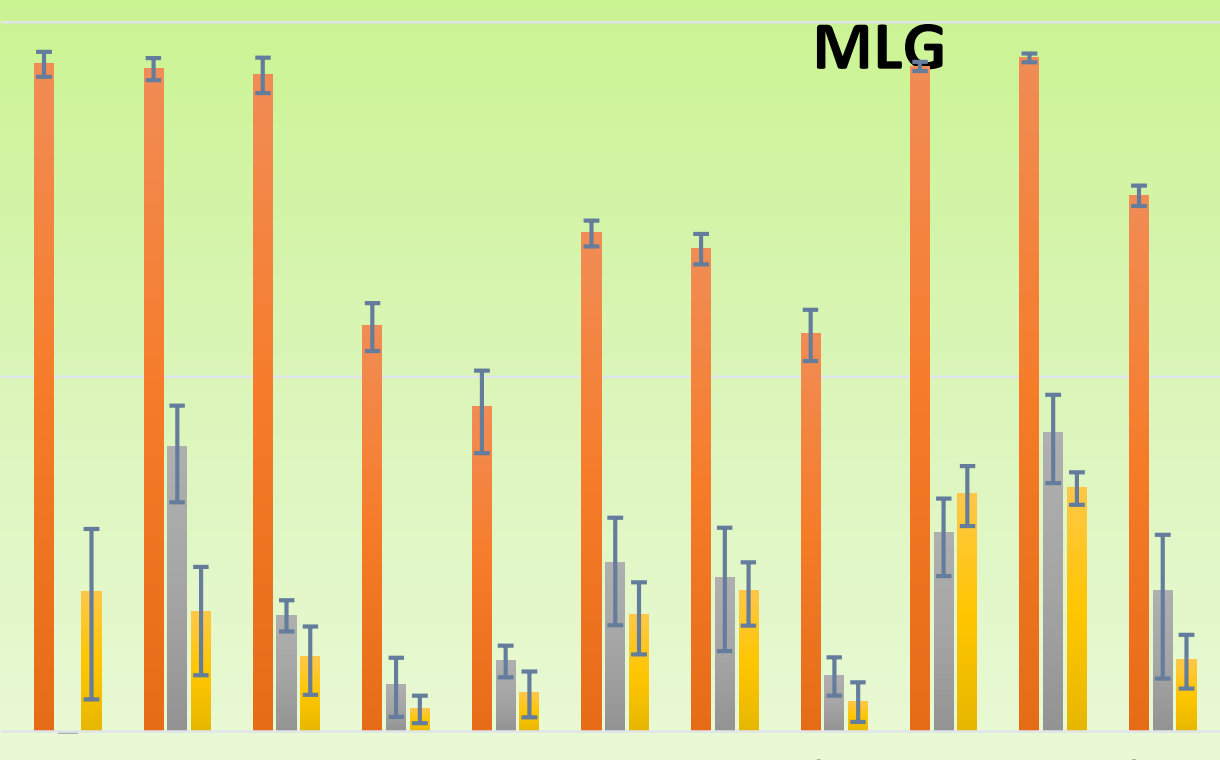

wt

$\Delta t f t A$

$\Delta t f t B$

$\Delta t f t A / \Delta t f t B$

\section{References}

1. Danial Samar et al., Identification and deletion of $T f t 1$, aPredicted Glycosyltransferase necessary for cell Wall MLG Synthesis in Aspergillus fumigatus PLoS ONE10(2) -2015.

2. Harshini Weerasinghe et al., Organism-wide studies into pathogenicity and morphogenesis in Talaromyces marneffei,Future microbiology-2016 